\title{
Comparison of $\mathrm{Ga}^{+}$and $\mathrm{SF}_{5}^{+}$primary ions for the molecular speciation of oxysalts in static secondary ion mass spectrometry (S-SIMS)
}

\author{
Rita Van Ham, ${ }^{a}$ Luc Van Vaeck, ${ }^{a}$ Freddy Adams ${ }^{a}$ and Annemie Adriaens ${ }^{* b}$ \\ ${ }^{a}$ University of Antwerp, Department of Chemistry, Universiteitsplein 1, B 2610 Antwerp, \\ Belgium \\ ${ }^{\boldsymbol{b}}$ Ghent University, Department of Analytical Chemistry, Krijgslaan 218-S12, B 9000 Ghent, \\ Belgium
}

Received 4th May 2005, Accepted 14th July 2005

First published as an Advance Article on the web 4th August 2005

Speciation of inorganic compounds by means of static secondary ion mass spectrometry (S-SIMS) aims at deriving the molecular composition of the analyte in the solid. The recent use of polyatomic primary ions, instead of the traditionally applied monatomic or diatomic projectiles, potentially offers an increase in secondary ion intensity and an increase in molecular specificity. This paper focuses on the comparison of $\mathrm{SF}_{5}{ }^{+}$and $\mathrm{Ga}^{+}$primary ion bombardment for the molecular speciation of inorganic oxysalts. The polyatomic primary ions are found to increase the total ion yield by a factor of 4-10. Furthermore, the relative intensities of the most structure-specific signals are increased in comparison with the low $\mathrm{m} / \mathrm{z}$ peaks under $\mathrm{SF}_{5}{ }^{+}$bombardment relative to $\mathrm{Ga}^{+}$. Although the formation of oxide fragments is promoted with polyatomic projectiles, the mass spectra significantly gain in information concerning the molecular specificity.

\section{Introduction}

The identification of the organic and inorganic constituents within one monolayer of some specific molecules at the surface of solids is vital to the understanding of many material properties. The direct determination of the molecular composition of inorganic compounds by means of signals referring to the intact analyte is called molecular speciation. At this moment, mass spectrometry (MS) in combination with microbeam ionization of solids, by means of photons in laser microprobe MS (LMMS) or by means of a limited dose of primary ions in S-SIMS, plays an important role in the continuing development of methods for molecular speciation with high lateral and/or depth resolution.

The specific advantage of S-SIMS is the capability of generating molecular information from the outer (few) monolayers at the surface of the sample. ${ }^{1}$ The limitation of the ion dose inherently implies that a relatively small number of secondary ions become available for analysis. Hence, nowadays, research in S-SIMS focuses on the improvement of this ion yield. In this respect, the relatively recent development of polyatomic primary ion bombardment as an alternative to the traditionally used monoatomic or small diatomic ions receives increasing attention. Polyatomic projectiles involve the simultaneous impact of several atoms within a distance of a few tenths of a nanometre. The simultaneous generation of overlapping collision cascades is expected to improve the recoil of adequate momentum to the surface component. On the one hand, the damage cross section determining the decay rate of molecular signals in S-SIMS is likely to increase for polyatomic projectiles compared with monatomic primary ions. ${ }^{2,3}$ On the other hand, polyatomic ion bombardment may ultimately lead to a FAB-like phase explosion in the subsurface, ${ }^{4}$ reminiscent of fast atom bombardment, and thereby improve the release of molecular species. Recent simulation supports the latter concept. $^{5}$

The literature data available on inorganic speciation using polyatomic bombardment is rather limited; nevertheless, a few studies are worth mentioning here. The study by Groenewold et al. focused on the analysis of $\mathrm{CuCl}$ and $\mathrm{CuCl}_{2}$ by using $\mathrm{Ga}^{+}$ and $\mathrm{ReO}_{4}{ }^{-}$primary ions. ${ }^{6}$ The polyatomic projectiles proved to be more adequate to yield information on the surface oxidation state. This was attributed to the lower penetration depth of the $\mathrm{ReO}_{4}{ }^{-}$projectile in comparison with $\mathrm{Ga}^{+}$. The study was further elaborated by Van Ham et al. including various binary salts and the use of $\mathrm{SF}_{5}{ }^{+}$as the primary ion beam. ${ }^{7}$

Van Stipdonk et al. showed increased chemical damage in the surface layers of $\mathrm{NaIO}_{3}$ under polyatomic, as opposed to monatomic, primary ion bombardment. ${ }^{3}$ A low dose $\left(10^{4}-10^{6}\right.$ ions $\mathrm{cm}^{-2}$ ) of $20 \mathrm{keV} \mathrm{CsI} \cdot \mathrm{Cs}^{+}$primary ions yielded only $\mathrm{IO}_{3}{ }^{-}$ and $\mathrm{NaIO}_{3} \cdot \mathrm{IO}_{3}{ }^{-}$as iodate specific anions. Most of the total ion current was carried by ions to be expected from NaI. Since XPS analysis of the iodate sample revealed only a minor amount of $\mathrm{NaI}$, the observed $(\mathrm{NaI})_{n} \cdot \mathrm{I}^{-}$peaks were assigned to beam-induced chemical damage. Comparison of different projectiles $(\mathrm{CsI})_{n} \cdot \mathrm{Cs}^{+}(n=0-2)$ at the same impact energy showed that the relative yield of the iodate type ions decreased with $n$. The reverse was true for the iodide-type ions. This confirmed increased chemical damage by larger polyatomic primary ions seen for $\mathrm{NaNO}_{3}$.

The same research group also studied the changes in the negative ion mass spectra of $\mathrm{NaBF}_{4}$ by the use of $\mathrm{Cs}^{+}$and $\mathrm{CsI}$. $\mathrm{Cs}^{+},(\mathrm{CsI})_{2} \cdot \mathrm{Cs}^{+}$and $(\mathrm{CsI})_{3} \cdot \mathrm{Cs}^{+}$(all with $20 \mathrm{keV}$ energy). ${ }^{8,9}$ The results with $\mathrm{Cs}^{+}$reflected the competition between two ion formation pathways observed in plasma desorption MS. ${ }^{10}$ One route involved emission of intact $\mathrm{BF}_{4}{ }^{-}$and its incorporation into larger ions, whereas the other generated $\mathrm{NaF} \cdot \mathrm{F}^{-}$type ions. Polyatomic primary ions proved to be more efficient for producing both high and low mass secondary ions. ${ }^{8}$ Interestingly, the relative yield enhancement of ions $\mathrm{BF}_{4}{ }^{-}$and $\mathrm{NaBF}_{4}$. $\mathrm{BF}_{4}{ }^{-}$reached a plateau value at high primary ion mass, whereas that of $(\mathrm{NaF})_{n} \cdot \mathrm{F}^{-}$continued to increase. This trend pointed to overlapping collision cascades. The intensity ratios of $\mathrm{NaF} \cdot \mathrm{F}^{-}$and $\mathrm{NaBF}_{4} \cdot \mathrm{BF}_{4}{ }^{-}$over $\mathrm{BF}_{4}{ }^{-}$were more sensitive to the number of atoms in the primary projectile than to the 
total energy deposited by the incident projectile. ${ }^{9}$ The secondary ion yield normalised on the number of atoms in the primary projectile showed a similar non-linear dependence on the primary projectile energy per mass, as described earlier for iodates and nitrates., ${ }^{3,11,12}$ Interestingly, the yield enhancement by larger polyatomic primary ions was larger for $\mathrm{NaF} \cdot \mathrm{F}^{-}$ ions, associated with beam-induced decomposition, than for the $\mathrm{BF}_{4}{ }^{-}$and $\mathrm{NaBF}_{4} \cdot \mathrm{BF}_{4}{ }^{-}$ions.

The purpose of this paper is to study the characteristic features of the mass spectra of oxysalts generated by $\mathrm{Ga}^{+}$ and $\mathrm{SF}_{5}{ }^{+}$primary ions. The following questions are to be addressed: (1) does the overall yield improve? (2) is there an increase in the relative importance of high $\mathrm{m} / z$ adducts? and (3) are low $m / z$ fragments and/or unspecific cluster ions promoted by the use of polyatomic ions? Attention is focused on a set of well-selected molecules such as alkali nitrates, nitrites, phosphates and hydrogen phosphates. Apart from the beam-induced damage, the nitrate and nitrite analogues have been chosen to compare the two guns in the case of so-called finespeciation, i.e., the distinction between salts with the same elements in a different oxidation state. The series of alkali hydrogen phosphates allows the speciation capabilities of both guns to be delineated for salts with the same elements in the same oxidation states but in different ratios. The possible effect of surface water on the S-SIMS data may cause confusion between the phosphates and the hydrogen phosphates. The works follows a previous study on the use of polyatomic primary ions for the analysis of binary salts. ${ }^{7}$

\section{Experimental}

Analyses were performed with a TOF-SIMS IV (ION-TOF, Germany) instrument, equipped with an ion reflector. Spectra were taken using a $\mathrm{Ga}^{+}$liquid metal ion source and an $\mathrm{SF}_{5}{ }^{+}$ electron ionization gun. The liquid metal ion source for the production of $\mathrm{Ga}^{+}$was operated at $25 \mathrm{kV}$ beam voltage in bunched mode with a pulse width of $20 \mathrm{~ns}$. This provided a sufficient mass resolution for better than nominal separation for ions with a mass-to-charge $(\mathrm{m} / \mathrm{z})$ ratio of up to 1000 . The 9 $\mathrm{keV} \mathrm{SF}_{5}{ }^{+}$primary ions were produced by an electron ionization source filled with $\mathrm{SF}_{6}$ at $3 \times 10^{-6}$ mbar. The diameter of the $\mathrm{Ga}^{+}$and $\mathrm{SF}_{5}{ }^{+}$beam on the sample was $2-5$ and $25 \mu \mathrm{m}$, respectively. The analysis time was $300 \mathrm{~s}$, allowing $3 \times 10^{6}$ spectra to be accumulated. The area of analysis was $300 \times 300$ $\mu \mathrm{m}^{2}$. The total ion dose was typically kept under $4 \times 10^{11}$ ions $\mathrm{cm}^{-2}$. Electron flooding was applied to compensate for the charging.

The samples were analyzed as pellets (surface $1 \mathrm{~cm}^{2}$, thickness $1-2 \mathrm{~mm}$ ), which were prepared by pressing pure salts in a dial under a pressure of 5-8 tons $\mathrm{cm}^{-2}$. The surface roughness was within $0.1 \mathrm{~mm}$. In order to avoid the adsorption of water from the air, the pellets were stored in a desiccator under vacuum or made just before analysis. A small piece with a flat surface was mounted in the TOF S-SIMS sample holder so that a vacuum of typically $10^{-8}$ mbar could be reached in a reasonable time.

The oxysalts $\mathrm{NaNO}_{2}{ }^{\mathrm{a}}, \mathrm{NaNO}_{3}{ }^{\mathrm{b}}, \mathrm{K}_{3} \mathrm{HPO}_{4}{ }^{\mathrm{c}}, \mathrm{K}_{2} \mathrm{HPO}_{4}{ }^{\mathrm{d}}$, and $\mathrm{KH}_{2} \mathrm{PO}_{4}{ }^{\mathrm{b}}$ were purchased from Janssen Chimica ${ }^{\mathrm{a}}$, Merck ${ }^{\mathrm{b}}$, Aldrich Chemical Company ${ }^{\mathrm{c}}$ and $\mathrm{UCB}^{\mathrm{d}}$.

\section{Results and discussion}

To facilitate the detailed comparison of $\mathrm{SF}_{5}{ }^{+}$and $\mathrm{Ga}^{+}$data for the various inorganic salts, we have made use of the total ion current (TIC) and the relative intensity of specific ions per given analysis time, defined as the $B$ ratio:

$$
B=\frac{I_{\mathrm{SF}_{5}^{+}}}{I_{\mathrm{Ga}^{+}}}
$$

where $I_{\mathrm{SF}^{+}}$is the intensity of the signal for a given $m / z$ in the $\mathrm{SF}_{5}{ }^{+}$spectra, and $I_{\mathrm{Ga}^{+}}$the signal of the corresponding ion in the $\mathrm{Ga}^{+}$spectra, both corrected for the ion dose. In order to describe the potential gain of molecular specificity with $\mathrm{SF}_{5}{ }^{+}$ versus $\mathrm{Ga}^{+}$in a more quantitative way, the ion intensity ratios (normalised within each spectrum) are compared for molecular (adduct) ions, structural fragments and cluster ions. Therefore, a parameter $R$ is defined as:

$$
R=\frac{\left(I_{1} / I_{2}\right)_{\mathrm{SF}_{5}^{+}}}{\left(I_{1} / I_{2}\right)_{\mathrm{Ga}^{+}}}
$$

with $I_{1}$ and $I_{2}$ intensities at different $m / z$ values.

To assist in the interpretation of the figures, it has been attempted to separate the "winners" (ions for which the polyatomic ions are beneficial) from the "losers". Therefore, whenever $R<1$, the inverted value is given a negative sign before plotting.

\section{$\mathrm{NaNO}_{3}$ and $\mathrm{NaNO}_{2}$}

The mass spectra taken with $\mathrm{Ga}^{+}$primary ions are given in Figs. 1 and 2 for $\mathrm{NaNO}_{3}$ and $\mathrm{NaNO}_{2}$, respectively. The mass spectral peak pattern for the cations reflects the features to be expected. Specifically, the generation of $\mathrm{NaOH}$ and $\mathrm{Na}_{2} \mathrm{O}$ related ions refers to the characteristic structural decomposition observed in all oxysalts:

$$
2 \mathrm{NaNO}_{3} \rightarrow \mathrm{Na}_{2} \mathrm{O}+\mathrm{N}_{2} \mathrm{O}_{5}
$$

Mono- and dimeric adducts of the original molecules are observed together with both $\mathrm{Na}^{+}$and $\mathrm{NaO}^{+}$ions. The combination of $\mathrm{NaNO}_{3}$ with the $\mathrm{Na}_{2} \mathrm{O}$ as a neutral building block occurs as well. As expected, the cationised $\mathrm{NaNO}_{2}$ molecules yield a significant signal in comparison with the cationised $\mathrm{NaNO}_{3}$, but the relative intensity in favour of the latter remains consistent with the availability in the sample. In the
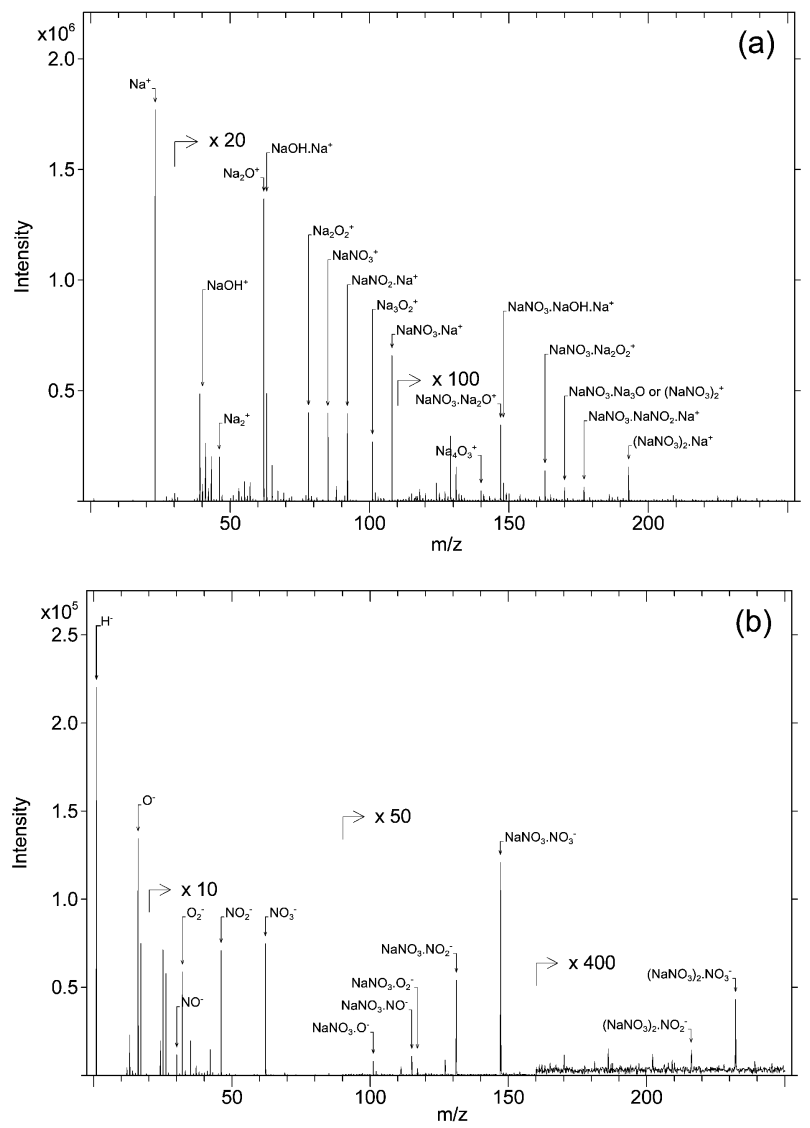

Fig. 1 Positive (a) and negative (b) ion mass spectra of $\mathrm{NaNO}_{3}$ under $\mathrm{Ga}^{+}$bombardment. 

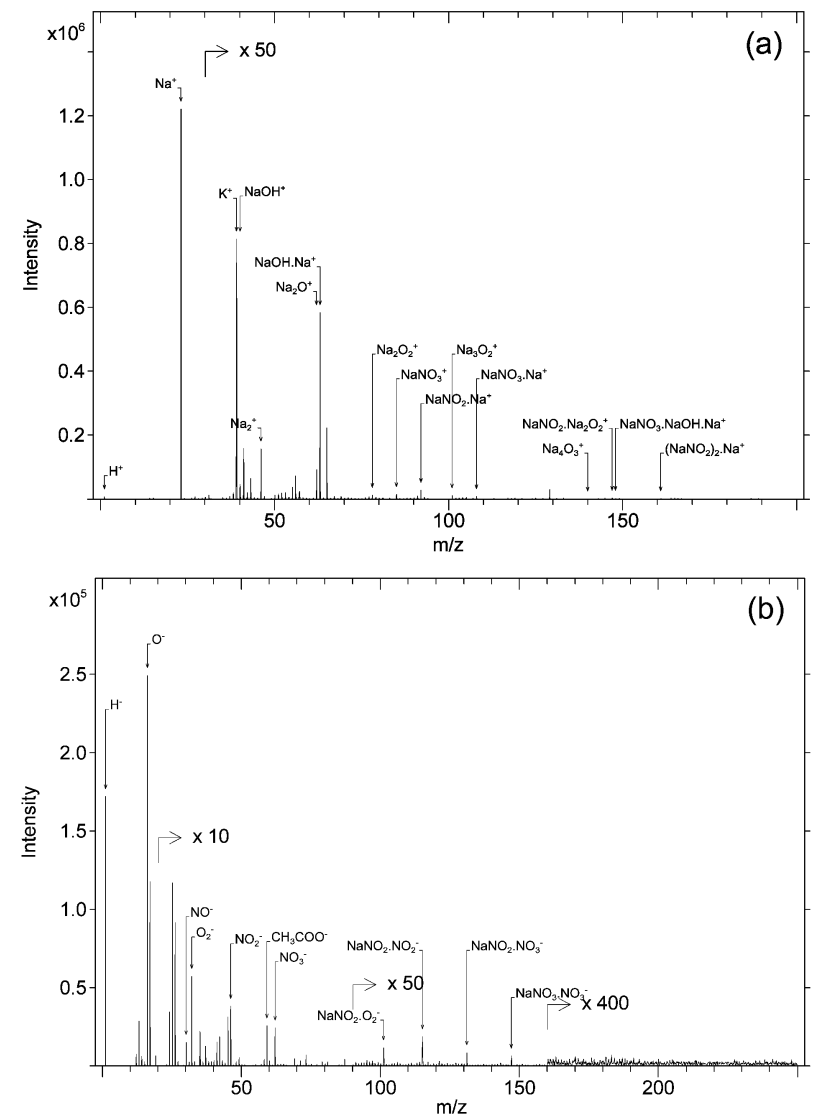

Fig. 2 Positive (a) and negative (b) ion mass spectra of $\mathrm{NaNO}_{2}$ under $\mathrm{Ga}^{+}$bombardment.

negative mode, the $\mathrm{NO}^{-}, \mathrm{NO}_{2}{ }^{-}$and $\mathrm{NO}_{3}{ }^{-}$ions are indicative of the nitrate whereas molecular adducts with reasonable intensity are available. In our experience, for a signal to be considered for use in practical applications, it must reach at least 1000 counts in $300 \mathrm{~s}$ or 3 counts $\mathrm{s}^{-1}$ acquisition time (cpsat) during the analysis of a pure product.

As to the distinction between sodium nitrate and nitrite, Fig. 2 shows that the nitrite has a substantially lower yield of the high $m / z$ ions than the nitrate. This holds true for the positive and negative ions. In particular, the signal from the cationised analyte does not even reach 3 cpsat for nitrite as opposed to the cationised ion of nitrate. In the negative mode, molecular adducts in both cases reach only the threshold for detection in pure products. The comparison of the relative intensities of the analyte adducts over those of the other form shows that both ratios, $\mathrm{NaNO}_{2} \cdot \mathrm{Na}^{+} / \mathrm{NaNO}_{3} \cdot \mathrm{Na}^{+}$as well as $\mathrm{NaNO}_{2}$. $\mathrm{NO}_{3}{ }^{-} / \mathrm{NaNO}_{3} \cdot \mathrm{NO}_{3}{ }^{-}$, are substantially in favour of the form analysed. Otherwise stated, the availability in the solid state improves the yield of the corresponding adduct. Hence, these ratios can be used to achieve fine speciation but reference spectra must be recorded under identical conditions. Spectra from a database are inadequate because the balance between availability in the sample and formation of the other stable form is rather delicate. Specifically, charge compensation is critical. It has been shown that the intensity ratio $\mathrm{NaNO}_{3}$. $\mathrm{NO}_{3}{ }^{-} / \mathrm{NaNO}_{3} \cdot \mathrm{NO}_{2}{ }^{-}$in nitrates goes from 0.41 to 0.72 without and with electron flooding. Also, the ratio $\mathrm{NO}_{2}{ }^{-} / \mathrm{NO}_{3}{ }^{-}$for nitrate rises from 0.71 to 1.14 without and with use of the flood gun. A reduction of the nitrate to the nitrite form is logically explained by the electrons striking the surface.

The mass spectra taken with $\mathrm{SF}_{5}{ }^{+}$are given in Figs. 3 and 4 for $\mathrm{NaNO}_{3}$ and $\mathrm{NaNO}_{2}$, respectively. With $\mathrm{SF}_{5}{ }^{+}$the total ion current (TIC) substantially increases, which allows the series of detected adducts to be extended. In the positive mode, dimers exceed the 3 cpsat criterion for nitrates with $\mathrm{SF}_{5}{ }^{+}$(only
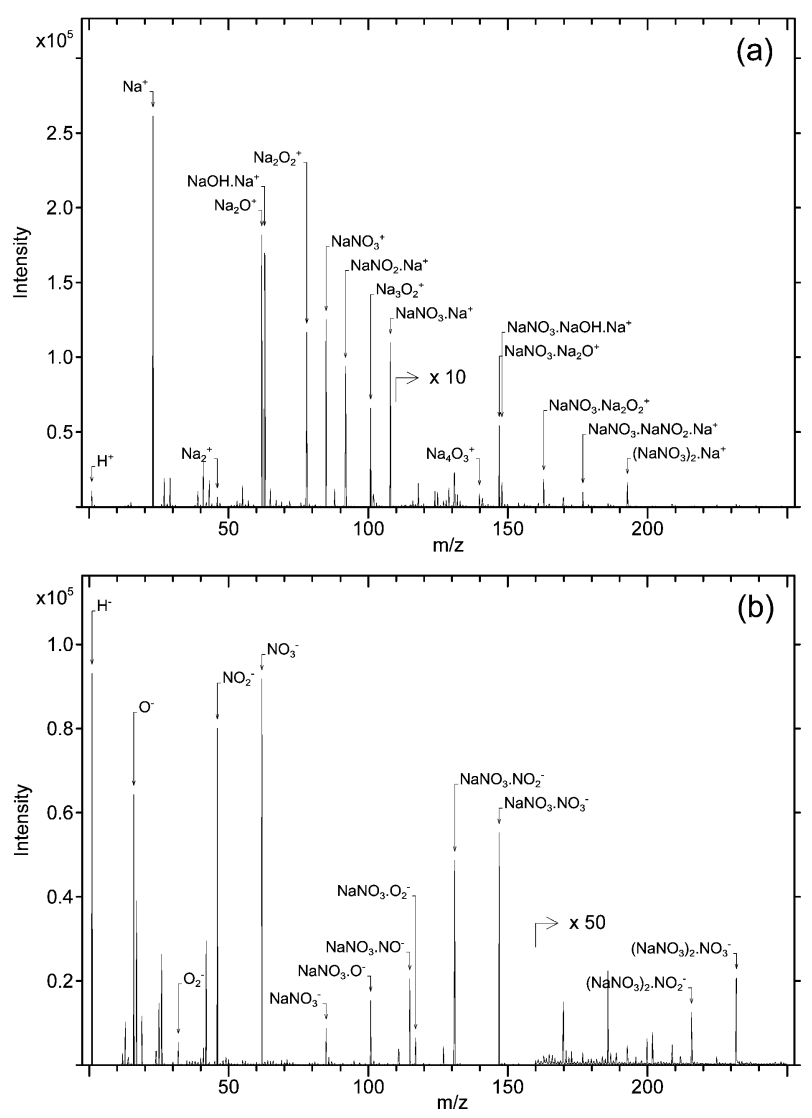

Fig. 3 Positive (a) and negative (b) ion mass spectra of $\mathrm{NaNO}_{3}$ under $\mathrm{SF}_{5}{ }^{+}$bombardment.

monomers with $\mathrm{Ga}^{+}$) and also trimers are practically useful for nitrates (only dimers with $\mathrm{Ga}^{+}$).
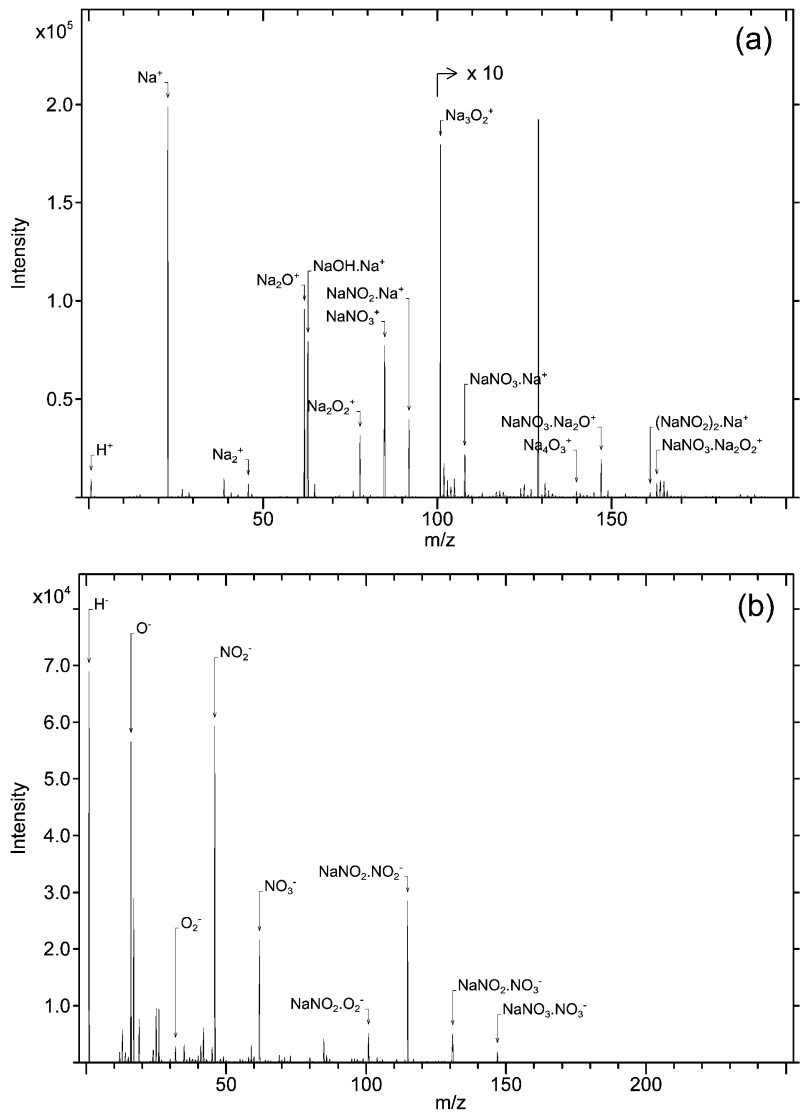

Fig. 4 Positive (a) and negative (b) ion mass spectra of $\mathrm{NaNO}_{2}$ under $\mathrm{SF}_{5}{ }^{+}$bombardment. 
Quantitatively expressed, the $B$ factor for $\mathrm{NaNO}_{2} \cdot \mathrm{Na}^{+}$ from nitrite is about 1400 and about 70 for $\mathrm{NaNO}_{3} \cdot \mathrm{Na}^{+}$from nitrate. Also for the negative ions, one additional adduct is seen (dimers against monomers for $\mathrm{Ga}^{+}$) for nitrate and nitrite. The $B$ factor for $\mathrm{NaNO}_{2} \cdot \mathrm{NO}_{2}{ }^{-}$and $\mathrm{NaNO}_{3} \cdot \mathrm{NO}_{3}{ }^{-}$is about 2000 and 200 for nitrite and nitrate, respectively. The potential gain in molecular specificity of the mass spectra taken with $\mathrm{SF}_{5}{ }^{+}$compared with $\mathrm{Ga}^{+}$is illustrated by the $R$ factor (relative peak intensities $\mathrm{SF}_{5}{ }^{+} / \mathrm{Ga}^{+}$) in Figs. 5 and 6 for $\mathrm{NaNO}_{2}$ and $\mathrm{NaNO}_{3}$, respectively. To avoid confusion between isobars such as $\mathrm{NaNO}_{2} \cdot \mathrm{NO}_{3}{ }^{-}$and $\mathrm{NaNO}_{3} \cdot \mathrm{NO}_{2}{ }^{-}$, the $\mathrm{NaNO}_{2} \cdot \mathrm{NO}_{2}{ }^{-}$and $\mathrm{NaNO}_{3} \cdot \mathrm{NO}_{3}{ }^{-}$ions have been used for normalisation of the signal intensities in nitrite and nitrate, respectively.

As to the positive ions, the relative importance of the ions based on the oxide fragments significantly increases with $\mathrm{SF}_{5}{ }^{+}$ projectiles. This observation confirms the data of Van Stipdonk et al. ${ }^{12}$ On the other hand, the strong decrease of the $\mathrm{Na}^{+}$ and $\mathrm{Na}_{2}{ }^{+}$intensities reflects the increase of the monomeric adduction contribution to the TIC. The relative importance of the dimeric adducts also decreases in comparison with the monomeric ones. A roughly similar picture is seen for the negative ions. The low $m / z$ ions $\mathrm{NO}^{-}$and, to a less extent, also $\mathrm{NO}_{2}{ }^{-}$and $\mathrm{NO}_{3}{ }^{-}$are serious "losers" for both analytes. The molecular ion production is disfavoured in the case of $\mathrm{NaNO}_{2}$, not for $\mathrm{NaNO}_{3}$. However, in both cases the monomeric adduct ion $\left(\mathrm{NaNO}_{2} \cdot \mathrm{NO}_{2}{ }^{-}\right.$and $\mathrm{NaNO}_{3} \cdot \mathrm{NO}_{3}{ }^{-}$for nitrite and nitrate, respectively) of the original analyte is the main "winner".

Summarizing, bombardment with $\mathrm{SF}_{5}{ }^{+}$projectiles improves the capability to distinguish between both analyets in comparison the $\mathrm{Ga}^{+}$. Table 1 lists the ratios of the characteristic ions to be used for molecular speciation. In particular, negative ion mass spectra taken with $\mathrm{SF}_{5}{ }^{+}$produce diagnostic peak ratios more different for nitrate and nitrite analytes than $\mathrm{Ga}^{+}$does. This holds true also for the signal intensity ratio $\mathrm{NO}_{2}{ }^{-} / \mathrm{NO}_{3}{ }^{-}$. The improvement in molecular specificity by $\mathrm{SF}_{5}{ }^{+}$projectiles is less dramatic for the positive than for the negative ion mass spectra.

\section{Potassium (hydrogen) phosphates}

Pellets of $\mathrm{K}_{3} \mathrm{PO}_{4}, \mathrm{~K}_{2} \mathrm{HPO}_{4}$ and $\mathrm{KH}_{2} \mathrm{PO}_{4}$ were measured under $\mathrm{Ga}^{+}$and $\mathrm{SF}_{5}{ }^{+}$ion bombardment on the same day. Fig. 7 lists
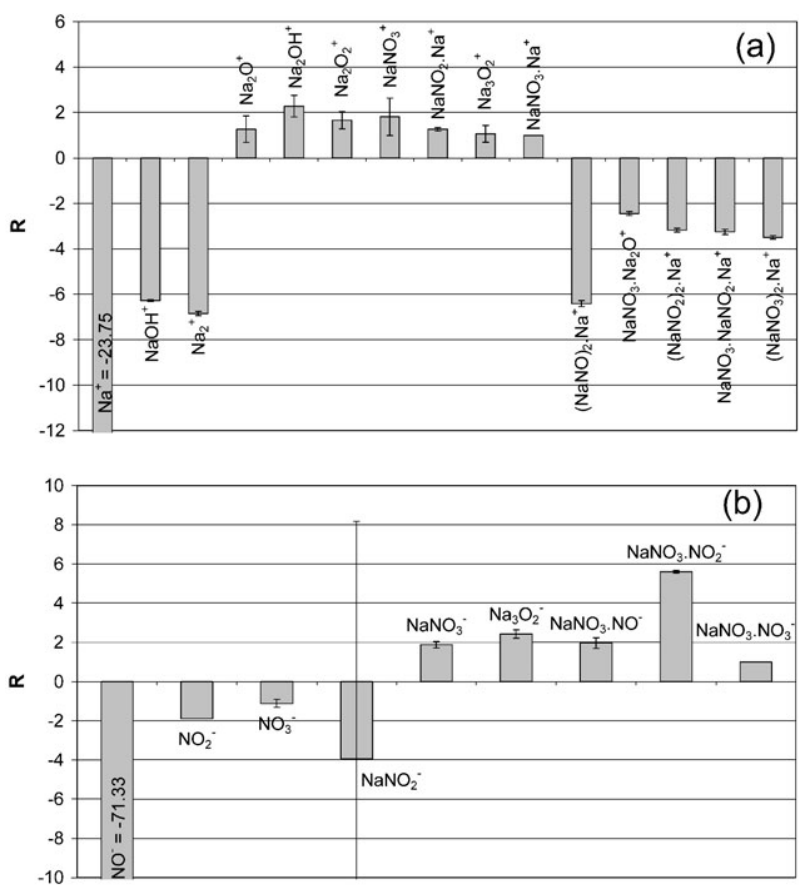

Fig. 5 Comparison of relative intensities ( $R$-factor) of diagnostic ions from $\mathrm{NaNO}_{3}$ under $\mathrm{SF}_{5}{ }^{+}$bombardment referenced to the ones under $\mathrm{Ga}^{+}$impact.
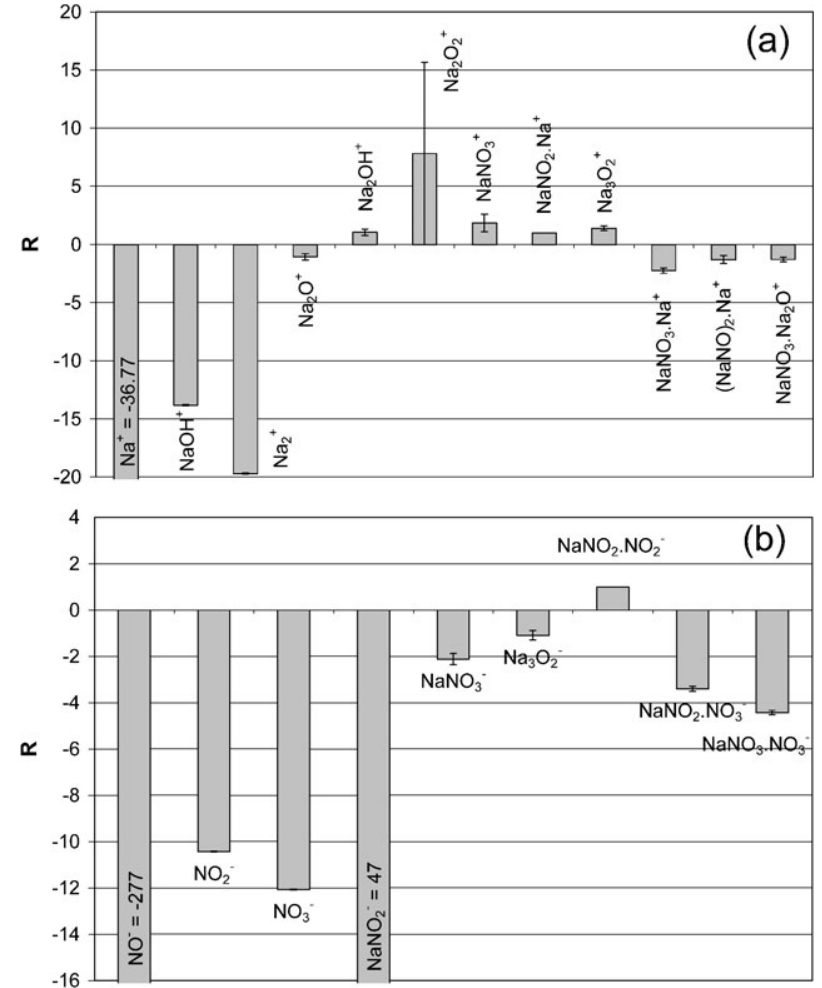

Fig. 6 Comparison of relative intensities ( $R$-factor) of diagnostic ions from $\mathrm{NaNO}_{2}$ under $\mathrm{SF}_{5}{ }^{+}$bombardment referenced to the ones under $\mathrm{Ga}^{+}$impact.

the positive ion spectra of $\mathrm{K}_{3} \mathrm{PO}_{4}$ using $\mathrm{SF}_{5}{ }^{+}$as found with $\mathrm{Ga}^{+}$and shows a similar pattern for both primary ions. The main diagnostic information comes from $\mathrm{K}_{3} \mathrm{PO}_{4} \cdot \mathrm{K}^{+}$and $\left(\mathrm{K}_{3} \mathrm{PO}_{4}\right)_{2} \cdot \mathrm{K}^{+}$. Once again, the $\mathrm{SF}_{5}{ }^{+}$primary ion bombardment increases the intensity of adduct ions from both the analyte $\left(\mathrm{K}_{3} \mathrm{PO}_{4} \cdot \mathrm{K}^{+}\right)$and the contaminant $\mathrm{K}_{2} \mathrm{CO}_{3} \cdot \mathrm{K}^{+}$with an average factor of 10 . Negative ion mass spectra contain little diagnostic information apart from $\mathrm{PO}_{x}{ }^{-}$signals. The $\mathrm{SF}_{5}{ }^{+}$ bombardment does not yield additional information for speciation analysis in comparison with $\mathrm{Ga}^{+}$. The absolute intensity of the $\mathrm{PO}_{x}{ }^{-}$ions increase substantially $(B=15)$ and the ratio of $\mathrm{PO}_{2}^{-} / \mathrm{PO}_{3}^{-}$inverts.

Fig. 8 describes the differences in ion yield by using $\mathrm{SF}_{5}{ }^{+}$and $\mathrm{Ga}^{+}$bombardment in a more quantitative manner. The $B$ factors $\left(I_{\mathrm{SF}^{+}} / I_{\mathrm{Ga}^{+}}\right)$show that the intensity gain of the oxide related species equals that of the molecular adducts $\mathrm{K}_{3} \mathrm{PO}_{4}$. $\mathrm{K}^{+}$. The huge RSD on the former $B$ factors for oxides is due to the variability in the $\mathrm{Ga}^{+}$spectra. The enhanced fragmentation into oxides of the analyte under $\mathrm{SF}_{5}{ }^{+}$bombardment is noted again. The $R$ factors, using the adduct $\mathrm{K}_{3} \mathrm{PO}_{4} \cdot \mathrm{K}^{+}$as reference evidence the increased molecular specificity of $\mathrm{SF}_{5}^{+}$mass spectra. In fact, only the monomeric adduct resides at the "winning" side of the plot while all the other signals manage to be "losers". The depreciation of the oxide species is small in comparison with $\mathrm{K}_{n} \mathrm{H}\left({ }_{3-n}\right) \mathrm{PO}_{4}$ adducts. Hence, it looks as though the intensity increase of the $\mathrm{K}_{3} \mathrm{PO}_{4} \cdot \mathrm{K}^{+}$happens at the expense of the less specific $\mathrm{K}_{n} \mathrm{H}\left({ }_{3-n}\right) \mathrm{PO}_{4}$ adducts, the presence of which is to be associated with surface water. Also, the dimeric adducts are "losers" as before for $\mathrm{NaNO}_{2}, \mathrm{NaNO}_{3}$ and $\mathrm{CuCl}_{2}$.

Figs. 9 and 10 compare the positive ion mass spectra taken with $\mathrm{SF}_{5}{ }^{+}$and $\mathrm{Ga}^{+}$from $\mathrm{K}_{2} \mathrm{HPO}_{4}$ and $\mathrm{KH}_{2} \mathrm{PO}_{4}$, respectively. Polyatomic projectiles produce essentially the same positive ions as $\mathrm{Ga}^{+}$but with higher intensity. Specifically, the gain for the monomeric adducts is a factor 4 and 40 for $\mathrm{K}_{2} \mathrm{HPO}_{4}$ and $\mathrm{KH}_{2} \mathrm{PO}_{4}$, respectively. However, as opposed to nitrates and nitrites, no additional high $\mathrm{m} / \mathrm{z}$ signals are observed with polyatomic projectiles in comparison to the $\mathrm{Ga}^{+}$ions. The 
Table 1 Characteristic peak intensity ratios to be used for distinction between $\mathrm{NaNO}_{2}$ and $\mathrm{NaNO}_{3}$ in the mass spectra recorded with Ga ${ }^{+}$and $\mathrm{SF}_{5}{ }^{+}$primary ions $(n=3)$

\begin{tabular}{|c|c|c|c|c|}
\hline & \multicolumn{2}{|l|}{$\mathrm{Ga}^{+}$} & \multicolumn{2}{|l|}{$\mathrm{SF}_{5}{ }^{+}$} \\
\hline & $\mathrm{NaNO}_{2}$ & $\mathrm{NaNO}_{3}$ & $\mathrm{NaNO}_{2}$ & $\mathrm{NaNO}_{3}$ \\
\hline $\mathrm{NO}_{2}^{-} / \mathrm{NO}_{3}^{-}$ & $2.9 \pm 0.3$ & $0.9 \pm 0.2$ & $3.5 \pm 1.2$ & $0.53 \pm 0.06$ \\
\hline $\mathrm{NaNO}_{2} \cdot \mathrm{NO}_{2}^{-} / \mathrm{NaNO}_{3} \cdot \mathrm{NO}_{3}^{-}$ & $3.8 \pm 0.5$ & $0.12 \pm 0.02$ & $19 \pm 10$ & $0.23 \pm 0.01$ \\
\hline $\mathrm{NaNO}_{2} \cdot \mathrm{Na}^{+} / \mathrm{NaNO}_{3} \cdot \mathrm{Na}^{+}$ & $3.9 \pm 0.9$ & $0.56 \pm 0.03$ & $10 \pm 5$ & $0.71 \pm 0.01$ \\
\hline
\end{tabular}

same holds true for the anion spectra, where the yield is also increased but no additional ions are found. Specifically, in the case of $\mathrm{KH}_{2} \mathrm{PO}_{4}$, the $\mathrm{KPO}_{3} \cdot \mathrm{PO}_{3}{ }^{-}$signal increases by a factor of 10 under $\mathrm{SF}_{5}{ }^{+}$bombardment and can now be considered for practical applications. The $\mathrm{P}^{-}$and $\mathrm{PO}^{-}$signals almost disappear under $\mathrm{SF}_{5}{ }^{+}$bombardment. If these ions are to be considered as indicative for beam-induced damage or destructive ionisation, polyatomic ions create a milder regime.

The evolution of relative intensities when changing from $\mathrm{Ga}^{+}$to $\mathrm{SF}_{5}{ }^{+}$is plotted in Fig. 11 for both analytes. Peak intensities are referenced on the cationised analyte molecules $\left(\mathrm{K}_{2} \mathrm{HPO}_{4} \cdot \mathrm{K}^{+}\right.$and $\mathrm{KH}_{2} \mathrm{PO}_{4} \cdot \mathrm{K}^{+}$, respectively). Once again, the elemental ions and $\mathrm{K}_{2}{ }^{+}$are serious "losers". A remarkable feature is the increased contribution of all ions derived from $\mathrm{K}_{2} \mathrm{O}(2)$ or $\mathrm{KOH}$ species. Amongst these ions, the $\mathrm{KOH} \cdot \mathrm{K}^{+}$is a significant winner. The good reproducibility of the corresponding $R$-factor contrasts with its variability seen before in the case of $\mathrm{K}_{3} \mathrm{PO}_{4}$. We explain this by the role of adsorbed surface water in the formation of these ions from $\mathrm{K}_{3} \mathrm{PO}_{4}$. It seems like the cleavage of the oxide moieties is favoured by the presence of the hydrogen in the analyte and this feature is intensified with the use of $\mathrm{SF}_{5}{ }^{+}$. As has been argued before, this does not reflect beam-induced damage since the fragments are structural in nature. Together with the increased contribu-
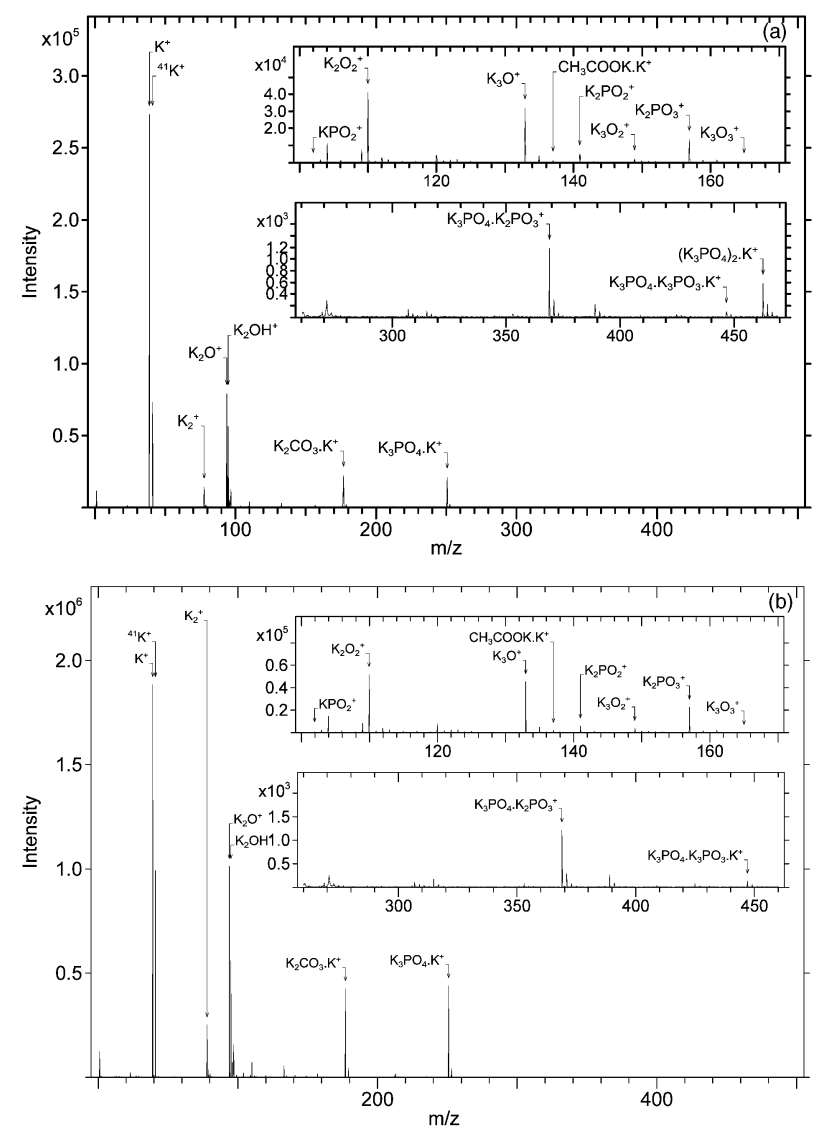

Fig. 7 Positive ion mass spectrum of $\mathrm{K}_{3} \mathrm{PO}_{4}$ under $\mathrm{SF}_{5}{ }^{+}$(a) and $\mathrm{Ga}^{+}$ (b) bombardment. tion of the oxide species comes, of course, enhanced importance of the cationised $\mathrm{KPO}_{3}$, which is the complementing part to the oxide in the analyte. Note that the normalised peak intensity of $\mathrm{KPO}_{3} \cdot \mathrm{K}^{+}$gains a factor 4 against only 1.5 in the case of $\mathrm{KH}_{2} \mathrm{PO}_{4}$ and $\mathrm{K}_{2} \mathrm{HPO}_{4}$, respectively.

The distinction between $\mathrm{KH}_{2} \mathrm{PO}_{4}$ and $\mathrm{K}_{2} \mathrm{HPO}_{4}$ must be based on the peaks from the cationised molecules. From Fig. 11 it can be seen that the molecular specificity of the mass spectrum increases with $\mathrm{SF}_{5}^{+}$for $\mathrm{K}_{2} \mathrm{HPO}_{4}$ because the intensity ratio of the "wrong analyte" form $\left(\mathrm{KH}_{2} \mathrm{PO}_{4} \cdot \mathrm{K}^{+} /\right.$ $\mathrm{K}_{2} \mathrm{HPO}_{4} \cdot \mathrm{K}^{+}$) decreases substantially. However, for $\mathrm{KH}_{2} \mathrm{PO}_{4}$, the situation becomes problematic because the $\mathrm{K}_{2} \mathrm{HPO}_{4}$. $\mathrm{K}^{+} / \mathrm{KH}_{2} \mathrm{PO}_{4} \cdot \mathrm{K}^{+}$increases, suggesting the "wrong" analyte. Although the normalised $\mathrm{K}_{3} \mathrm{PO}_{4} \cdot \mathrm{K}^{+}$is a significant winner, confusion with the pure phosphate sample is unlikely since $\mathrm{K}_{n} \mathrm{H}_{3-n} \mathrm{PO}_{4}$ adducts are absent. However, problems are to be expected with mixtures. Once again, the dimeric adducts are all losers with $\mathrm{SF}_{5}{ }^{+}$(up to a factor of 8). In conclusion, $\mathrm{SF}_{5}{ }^{+}$ bombardment seems to stimulate the formation of oxide species and disfavour the generation of dimeric adducts. The molecular specificity is increased in the case of $\mathrm{K}_{2} \mathrm{HPO}_{4}$ by the increased generation of the relevant adducts but $\mathrm{KH}_{2} \mathrm{PO}_{4}$ shows the opposite trend.

\section{Conclusions}

The potential benefits arising from the use of polyatomic $\mathrm{SF}_{5}{ }^{+}$ primary ions have been evaluated in comparison the $\mathrm{Ga}^{+}$ bombardment for selected oxysalts. It has been demonstrated that polyatomic ions give a substantial gain in the total ion
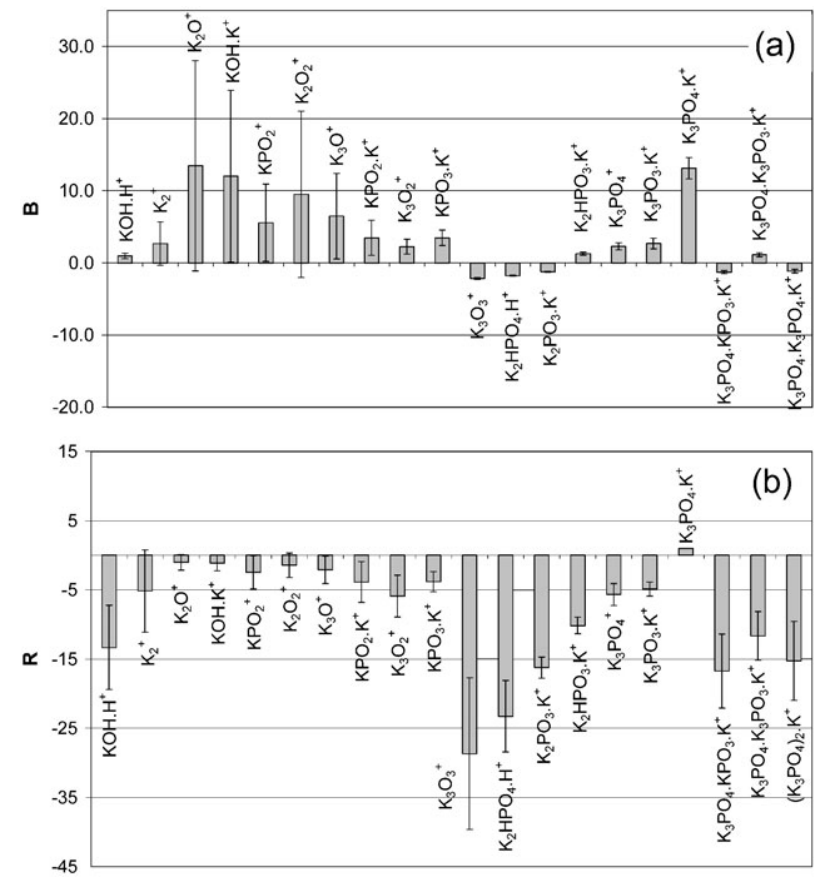

Fig. 8 Comparison of absolute ( $B$-factor, (a)) and relative intensity ratios ( $R$-factor, (b)) of diagnostic ions from $\mathrm{K}_{3} \mathrm{PO}_{4}$ under $\mathrm{SF}_{5}{ }^{+}$ bombardment referenced to the ones under $\mathrm{Ga}^{+}$impact. 

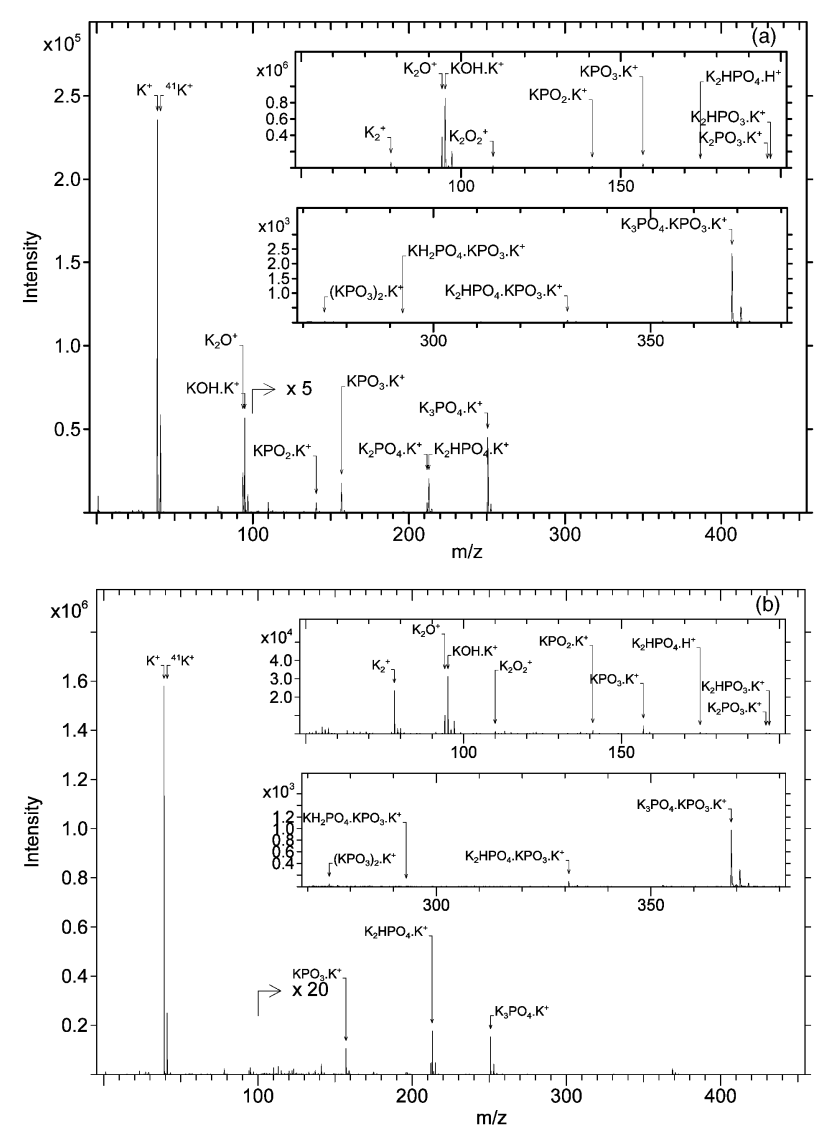

Fig. 9 Positive ion mass spectrum of $\mathrm{K}_{2} \mathrm{HPO}_{4}$ under $\mathrm{SF}_{5}{ }^{+}$(a) and $\mathrm{Ga}^{+}$(b) bombardment.
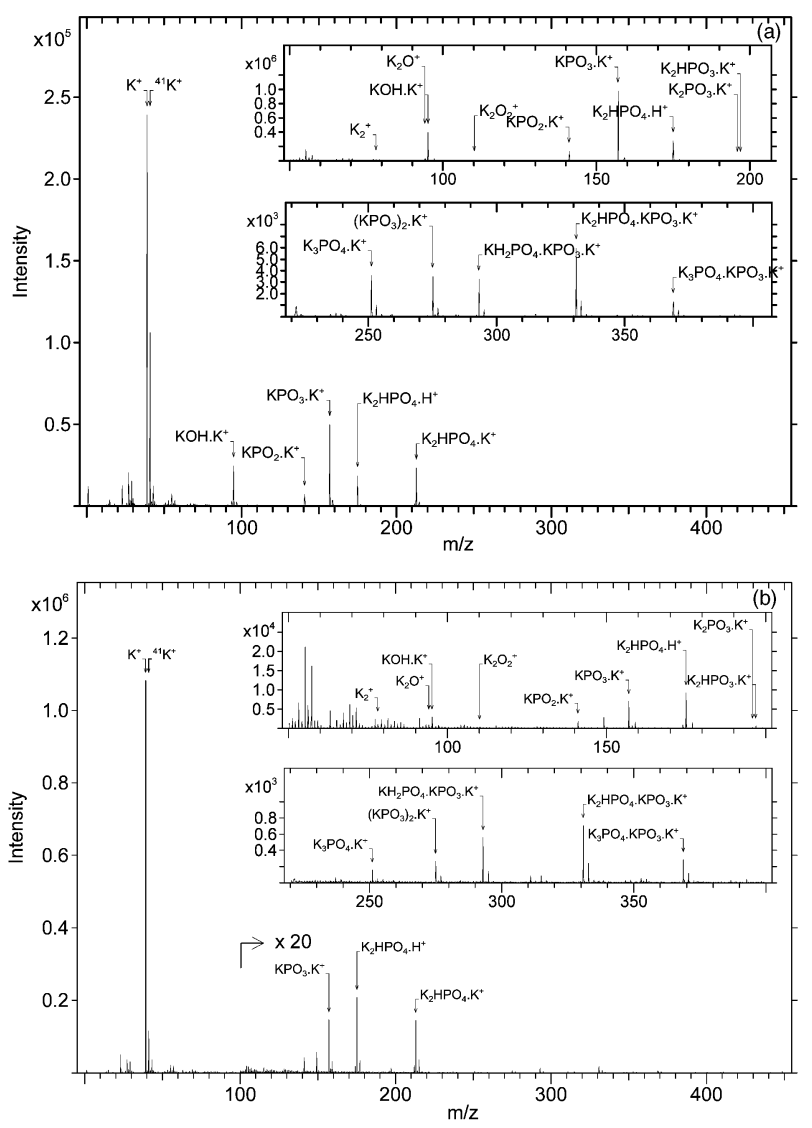

Fig. 10 Positive ion mass spectrum of $\mathrm{KH}_{2} \mathrm{PO}_{4}$ under $\mathrm{SF}_{5}{ }^{+}$(a) and $\mathrm{Ga}^{+}$(b) bombardment.
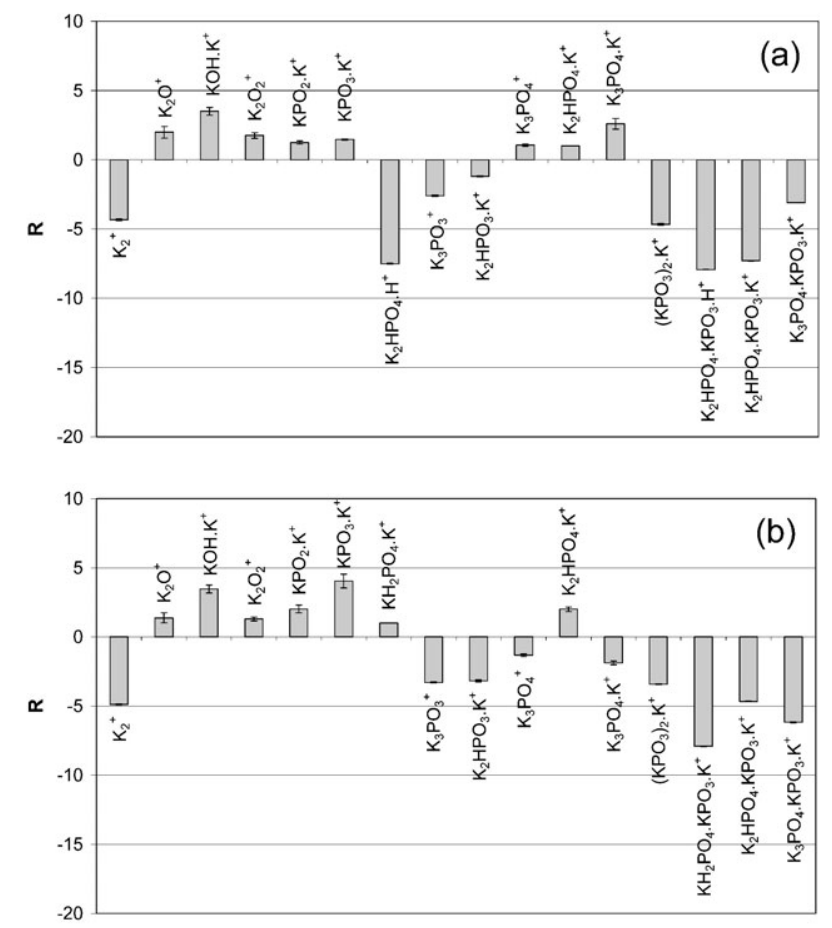

Fig. 11 Comparison of relative intensity ratios by $\mathrm{R}$-factor of diagnostic ions from $\mathrm{K}_{2} \mathrm{HPO}_{4}$ (a) and $\mathrm{KH}_{2} \mathrm{PO}_{4}$ (b) for the positive ions under $\mathrm{SF}_{5}{ }^{+}$bombardment referenced to the ones under $\mathrm{Ga}^{+}$impact.

current by a factor $4-10$, depending on the analogue under study. Equally important is the significant improvement in molecular specificity of the mass spectra taken under polyatomic bombardment. Specifically, the adduct ions are of particular diagnostic interest for speciation. Their relative contribution to the total ion current systematically increases when $\mathrm{SF}_{5}{ }^{+}$instead of $\mathrm{Ga}^{+}$ions are used. As a result, bombarding the surface with $\mathrm{SF}_{5}{ }^{+}$primary ions is beneficial in distinguishing between the different hydrogen phosphates and between nitrites and nitrates. At the same time, a polyatomic primary ion beam tend to decrease the relative importance of the elemental ions.

The reported experiments have focused on a preliminary assessment of the practical advantages of $\mathrm{SF}_{5}{ }^{+}$primary ions in comparison with $\mathrm{Ga}^{+}$for the speciation of inorganic oxysalts. Further and fundamental work will be needed to pinpoint the most interesting type of primary ion but our experimental assessment already confirms that the use of polyatomic primary ions becomes one of the most promising developments in the continuing search for yield improvement in S-SIMS.

\section{Acknowledgements}

This work was supported in part by the Belgian Office for Scientific, Technical and Cultural Affairs (IUAP 5) and by FWO, Brussels, Belgium (research projects G.0090.98 and G.0172.00).

\section{References}

1 R. Van Ham, L. Van Vaeck, F. Adams and A. Adriaens, Anal. Chem., 2004, 76(9), 2609.

2 G. S. Groenewold, A. K. Gianotto, J. E. Olson, A. D. Appelhans, J. C. Ingram, J. E. Delmore and A. D. Shaw, Int. J. Mass Spectrom. Ion Processes, 1998, 174, 129.

3 M. J. Van Stipdonk, V. Santiago, E. A. Schweikert, C. C. Chusuei and D. W. Goodman, Int. J. Mass Spectrom., 2000, 197, 149.

4 J. Sunner, A. Morales and P. Kebarle, Int. J. Mass Spectrom. Ion Processes, 1988, 86, 169 
5 K. D. Krantzmann, Z. Postawa, B. J Garrison, N. Winograd, J. S. Stuart and J. A. Harrison, Nucl. Instrum. Meth. Phys. Res. B, 2001, 180, 159.

6 G. S. Groenewold, A. D. Appelhans, G. L. Gresham, J. C. Ingram and A. D. Shaw, Int. J. Mass Spectrom. Ion Processes, 1998, 178, 19.

7 R. Van Ham, L. Van Vaeck, A. Adriaens, F. Adams, B. Hodge and G. Groenewold, J. Anal. Atom. Spectrom., 2002, 17(8), 753.

8 M. J. Van Stipdonk, R. D. Harris and E. A. Schweikert, Rapid Commun. Mass Spectrom., 1997, 11, 1794.
9 M. J. Van Stipdonk, V. Santiago and E. A. Schweikert, Int. J. Mass Spectrom., 1999, 34, 554.

10 M. J. Van Stipdonk, J. B. Shapiro and E. A. Schweikert, Vacuum, 1995, 46, 1227

11 M. J. Van Stipdonk, D. R. Justus, V. Santiago and E. A. Schweikert, Rapid Commun. Mass Spectrom., 1998, 12, 1639.

12 M. J. Van Stipdonk, in TOF-SIMS: Surface Analysis by Mas Spectrometry, eds. J. C. Vickerman and D. Briggs, IM Publications, Chichester, UK, 2001, p. 309 